\title{
What Makes Policy Complex?
}

\author{
Roman Senninger, Aarhus University ${ }^{\dagger}$
}

\begin{abstract}
Previous research finds that policy complexity affects important political processes including legislative delegation and policy diffusion. However, policy complexity is not directly observable and the search for a reasonable proxy constitutes a major challenge for scholars. This research note presents a concise and measurable definition of complex policy based on two aspects: a policy's textual sophistication and its ties to other rules and regulations. Using crowdsourcing and a pairwise comparison framework it is shown that the proposed defining features are crucial for humans' understanding of policy text. The proposed definition is then operationalized using a large corpus of European Union rules and is shown to outperform alternative operationalizations of policy complexity in predicting the level of legislative delegation.
\end{abstract}

Word count: 3988 (incl. including tables, figures, footnotes, references)

\footnotetext{
${ }^{\dagger}$ Department of Political Science. Contact: rsenninger@ps.au.dk. Earlier versions of this paper have been presented at EPSA 2019, APSA 2019, and Harvard University. I want to thank Jason Anastasopoulos, Jens Blom-Hansen, Steffen Hurka, Heike Klüver, Stefan Müller, Fritz Sager, Bruno Castanho Silva, and Christian Rauh.
} 


\section{Introduction}

Policy complexity affects many important political processes including delegation and policy diffusion (Kiewiet and McCubbins, 1991; Epstein and O'Halloran, 1999; Braun and Gilardi, 2009; Makse and Volden, 2011). However, policy complexity is not directly observable and is therefore difficult to capture. Researchers rely on different measures, including readability scores or the number of articles, but most prior research only looks at a single aspect of policy complexity at a time. Below I argue and empirically validate that a policy's complexity is best defined by two aspects: its textual sophistication and the number of ties to other policies. The findings are important because they emphasize the role of both internal (i.e., textual) and external (i.e., relational) characteristics in explaining what makes policy difficult to understand. More broadly, they have implications for our understanding of the causes and consequences of complexity in policy-making.

\section{Defining complex policies ${ }^{1}$}

While some scholars argue that policy complexity depends on the length and detail of a policy (Ehrlich, 2011), others say that policy complexity is the result of the increasing number of relations between policies (Krehbiel, 1991; Adam et al., 2019). The former count the number of articles and words or rely on readability indexes such as the widely used Flesch Reading Ease formula. The latter investigate the complexity of policies through document network analysis (Katz et al., 2020). Crucially, most prior research focuses on a single aspect of policy complexity at a time.

My definition integrates two approaches. I define complex policies as those that have a high level of textual sophistication and a large number of ties to other policies. For

\footnotetext{
${ }^{1}$ It is important to note that this research note is concerned with the definition, operationalization, and measurement of what makes individual policy (i.e., laws, rules, and regulations) complex. The approach is more fine-grained than previous work that lumps laws together in policy issue areas suggesting that some areas are more complex than others (Epstein and O'Halloran, 1999; Nicholson-Crotty, 2009).
} 
individuals who want or need to engage with a policy there is no way around reading the text of the policy. Reaching a good understanding of the policy can be straightforward if it is written in an accessible manner. By contrast, a policy with a high level of textual sophistication makes it harder for the reader to understand. There exist many potential sources of textual sophistication. The characteristics that contribute to making a text more complex are text length, the use of longer words, the use of uncommon words, and the use of more complex syntactic and grammatical structure (Benoit, Munger and Spirling, 2019). Findings from different fields including medicine, communication science, and political science provide evidence that textual sophistication matters a great deal for humans' understanding of text (Leroy, Helmreich and Cowie, 2010; Tolochko, Song and Boomgaarden, 2019; Bischof and Senninger, 2018, 2022).

The second defining feature of complex policies goes beyond a policy's own characteristics and considers its wider context. This means potential cross references to other laws, rules, and regulations. The reason why ties to other policies are considered to be important is that they provide information that is relevant to fully understanding a policy. The decision to draft a new policy is very often motivated by insufficiencies of already existing policies. However, instead of withdrawing insufficient policies and replacing them with new and better policies, a process of policy layering or policy accumulation is increasingly common (Adam et al., 2019). Whenever two polices build upon each other or regulate very similar policy domains, it is likely that the newer policy makes reference to the older policy to describe the relation between the two (Krehbiel, 1991). A large number of references to other policies can make it more difficult to reach a full understanding of a policy because the consideration of additional related policies is required. 


\section{Empirical Roadmap}

The central proposal of this research note is that both textual sophistication and ties with other policies should be used to capture policy complexity. In the following, I first validate the proposed defining features of complex policy by showing that they are crucial for humans' understanding of policy. This part builds on and expands the workflow presented by Benoit, Munger and Spirling (2019). Thereafter, the proposed definition is operationalized using a large corpus of policies, and it is shown to outperform alternative operationalizations in predicting a theoretically relevant outcome, namely the level of legislative delegation. Both empirical exercises are conducted in the context of the European Union because it constitutes a large and important jurisdiction that has law-making powers in a broad range of policy areas. ${ }^{2}$ The flowcharts in Figure 1 provide information about the individual steps of the two empirical tests.

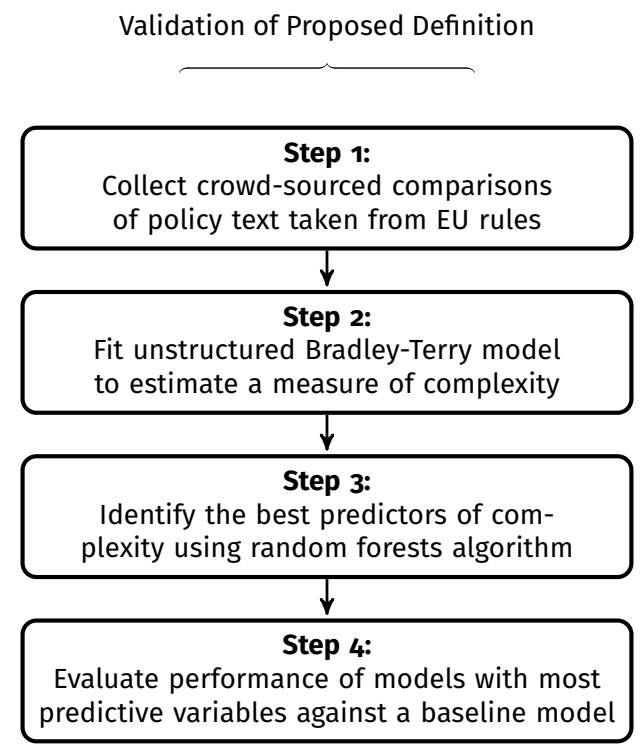

Testing Performance in Predicting Delegation

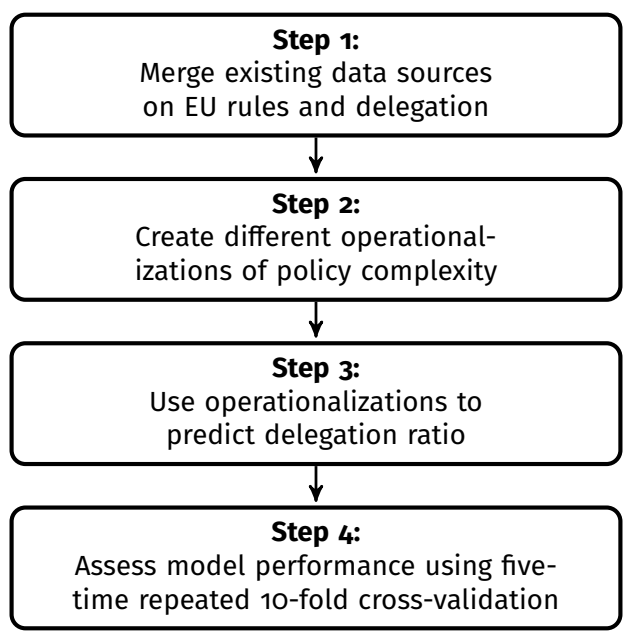

Figure 1: Individual steps of the empirical tests

\footnotetext{
${ }^{2}$ Section $A$ in the Supplementary Information reviews current practices as regards the definition and operationalization of policy complexity in the European Union. Section B provides an introduction to delegation in the context of the European Union.
} 


\section{Validation of proposed defining features}

Step 1: First, human judgments of the relative complexity of policy texts using crowdsourcing were collected. The approach involves non-experts who were asked to complete micro-tasks and works particularly well for identifying (latent) document characteristics (Carlson and Montgomery, 2017). The data consist of comparable short passages of text taken from recitals of European Union rules (Thomson et al., 2012). Recitals are listed before the articles of a policy act and state the reasons for the provisions, principles, and assumptions on which the act is based. ${ }^{3}$ From this text corpus, text snippets of varying length were randomly drawn. Following a stratified sampling method, the snippets drawn for comparison were constrained to groups of the same number of sentences and a similar number of characters to avoid comparisons in which coders simply select the one noticeably shorter than the other. ${ }^{4}$ Participants were recruited using the crowdsourcing platform Prolific. The sample is representative of the population of the United Kingdom using proportional cross-stratification on sex, age, and ethnicity. 597 individuals participated in the task..$^{5}$ Upon accepting the task, participants were shown a description of the task and a number of examples (see Figure SI 2 and the upper panel in Figure SI 3). Each respondent was asked to compare 15 randomly assigned pairs (two pairs for the purpose of attention checking). To screen respondents' attention, instructive manipulation checks were used (see lower panel in Figure SI 3). For the main analysis, I exclude respondents who failed to pass the attention checks leading to 536 participants and a total of 6962 comparisons. The average number of

\footnotetext{
${ }^{3}$ For more information about recitals please consult Section $A$ in the Supplementary Information. The rationale for using the text from recitals in the validation exercise is described in Section $G$ in the Supplementary Information.

4Please see Table SI 1 in the Supplementary Information. Text snippets which were outside the 0-121 range of the Flesch Reading Ease measure were dropped, as a simple way to remove very unusual texts. This preprocessing resulted in 1340 snippets which were linked together so that within each group every snippet meets one snippet in a comparison that meets another snippet.

${ }^{5}$ Participants were paid $£ 7.17$ per hour, which lies above the minimum reward per hour ( $\left.£ 5.5\right)$ suggested by Prolific.
} 
judgments per snippet is 5.1.

Step 2: The second step is to estimate the underlying complexity using the model for pairwise comparisons developed by Bradley and Terry (1952). The Bradley-Terry model assumes that the odds that snippet ${ }_{i}$ beats snippet ${ }_{j}$ are $\alpha_{i} / \alpha_{j}$, where $\alpha_{i}$ and $\alpha_{j}$ are parameters representing the 'easiness' of snippets, as respondents were asked which text snippet was easier to understand. The model can be expressed in logit form: $\operatorname{logit}[\operatorname{Pr}(i$ easier than $j)]=\lambda_{i}-\lambda_{j}$, where $\lambda_{i}=\log \alpha_{i}$ for all $i$. Fitting the equation to the pairwise data results in estimates of $\lambda_{i}$ for each text snippet, representing an unconditional estimate of that text's relative easiness. ${ }^{6}$

Step 3: The next step is to select potential predictors of this outcome, considering a model of the form: $\lambda_{i}=\sum_{i=1}^{p} \beta_{i} x_{i}+U_{i}$, in which easiness of each snippet $i$ is related to explanatory variables $x_{i}, \ldots, x_{p}$ through a linear predictor with coefficients $\beta_{1}, \ldots \beta_{p}$. $U_{i}$ represents independent errors (Turner and Firth, 2012). The estimated coefficients $\hat{\beta}$ indicate the marginal effect of each covariate on the perceived relative easiness of the text snippets. To represent textual sophistication, the absolute number of words and characters are considered. In addition, several variables that are part of the best model to explain textual complexity as presented in Benoit, Munger and Spirling (2019) are used. These are the mean number of characters per word, the mean number of characters per sentence, and the least frequent word's relative frequency based on the Google books data set. Finally, I add the Flesch Reading Ease, a common readability measure, determined by the number of words and the average number of syllables per word. To represent the second defining feature of complex policy, it was manually coded whether a text snippet refers to any existing legal acts or additional documents including treaties, conventions, communications, and resolutions. The variable comes in two versions. The first version is binary coded and indicates whether a text snippet includes

\footnotetext{
${ }^{6}$ In some cases a snippet never wins or never loses a competition raising the issue of complete separation. To address this, the bias-reduction technique embedded in the Bradley-Terry2 R package (Turner and Firth, 2012) was applied.
} 
a reference to any rules or documents. The second version indicates the number of such references. The appearance and number of abbreviations are also considered. By convention, recitals can start with the word 'Whereas'. For each text snippet it was recorded whether this is the case or not. All variables are listed in Table $1 .^{7}$

\begin{tabular}{|c|c|}
\hline Description & Covariate name \\
\hline $\begin{array}{l}\text { Textual Sophistication } \\
\text { Number of words } \\
\text { Mean characters per word } \\
\text { Mean characters per sentence } \\
\text { Google Books baseline usage } \\
\text { Flesch Reading Ease }\end{array}$ & $\begin{array}{c}\text { n_token } \\
\text { meanWordChars } \\
\text { meanSentenceChars } \\
\text { google_min } \\
\text { Flesch } \\
\end{array}$ \\
\hline Description & Covariate name \\
\hline $\begin{array}{l}\text { Ties between policies } \\
\text { Reference to other regulation } \\
\text { No. of references to other regulation }\end{array}$ & $\begin{array}{c}\text { reg_ref } \\
\text { reg_ref_count }\end{array}$ \\
\hline Description & Covariate name \\
\hline $\begin{array}{l}\text { Additional covariates } \\
\text { Text snippet with abbreviations } \\
\text { No. of abbreviations } \\
\text { Text snippet with 'Whereas' }\end{array}$ & $\begin{array}{c}\text { abr } \\
\text { abr_count } \\
\text { whereas }\end{array}$ \\
\hline
\end{tabular}

To assess the predictive power of the listed covariates, random forest models with 1000 trees were used. Random forests are chosen because they parsimonious, general, and less prone to overfitting (Lantz, 2015). They produce estimates of the relative importance of each variable which is useful information for selecting the best predictors of easiness of text snippets. Figure SI 5 ranks the variables' importance according to the value of the increase in mean squared error (MSE) as a result of a variable being permuted. At each node in each tree, three random variables were tried for the regression. This showed that some of the variables used in previous research also matter for predicting the easiness of short passages of text from recitals (especially the mean characters per sentence). Even more important are the absolute number of words. The mean characters per word also matter. These results provide evidence that textual so-

\footnotetext{
${ }^{7}$ For descriptive statistics please consult Table SI 3. Figure SI 4 shows correlations between variables.
} 
phistication is important for humans' understanding of policy text. In addition, it shows that ties with other rules and regulations matter as well. The variable representing the number of references to existing rules and documents contributes to the prediction of the outcome fourth most. When permuting the values of the number of references to other documents over the data, the increase in the mean squared error is $11 \%$. For the binary predictor, the increase is $12 \%$.

Step 4: Finally, I use the most predictive variables to fit structured models and assess their performance in predicting the pairwise contests. Because of its frequent use I compare the models against a baseline model that includes the widely used Flesch Reading Ease score as its only covariate (Model 1). Model 2 includes the two most predictive variables of textual sophistication. These are the number of words and the mean characters per sentence. Model 3 keeps the two variables to capture textual sophistication but adds the number of ties with other rules and documents. This third model captures both of my defining features of policy complexity and performs best, with the lowest Akaike information criterion (AIC) (9205.2) and the highest proportion of pairwise comparisons correctly predicted (0.772). ${ }^{8}$ For the first model, we see that the AIC is 9613.2 , and the augmented proportion of contests in the data correctly predicted is 0.676. Model 2 outperforms the first model with a lower AIC (9374.4) and a higher proportion of pairwise comparisons correctly predicted (0.752). 9

\begin{tabular}{lcc}
\hline \hline Model & AlC & Accuracy \\
\hline Model 1: Flesch Reading Ease & 9613.2 & 0.676 \\
Model 2: Number of words, Mean characters per sentence & 9374.4 & 0.752 \\
Model 3: Number of words, Mean characters per sentence, No. of references to other regulation & 9205.2 & 0.772 \\
\hline
\end{tabular}

Table 2: Model performance

\footnotetext{
${ }^{8}$ As discussed in Benoit, Munger and Spirling (2019), the upper bound of what any model can achieve as regards performance is dependent on agreement between crowd-coders in their ratings of text snippets and the number of contests. The average upper bound of performance for a model is 0.78 (or $78 \%$ ) correctly predicted.

${ }^{9}$ Table SI 4 presents the performance of an alternative approach combining the FRE and references to other regulation which is outperformed by Model 3. Hence, the FRE seems to be a rather poor measure of textual sophistication in the given context.
} 
It is important to note that both defining features matter for our understanding of policy text, as a model that only includes textual sophistication is clearly outperformed by a model that features both textual sophistication and ties to other rules. To demonstrate the face validity of the results, text boxes in Section E in the Supplementary Information present text snippets used in the pairwise comparisons which the best performing model identified as having a very low, an average, and a very high level of complexity, respectively. ${ }^{10}$

\section{Testing Performance in Predicting Delegation}

In the following, I test how different operationalizations of policy complexity perform in predicting the level of legislative delegation. Step 1: For this purpose, several data sources were merged. For the level of legislative delegation, data comes from Anastasopoulos and Bertelli (2020), who use machine learning techniques to measure the amount of delegation to the European Commission and member states' national administrations in directives and regulations. The predicted values for each provision, effectively articles and sub-articles, are aggregated so that the dependent variable gives the delegation ratio $\left(\Delta_{i}\right)$ for each law $i$. The delegation ratio $\left(\Delta_{i}\right)$ represents the number of provisions delegating authority $D_{i}$ divided by the total number of provisions in the law $P_{i}\left(\Delta_{i}=\frac{D_{i}}{P_{i}}\right) .{ }^{11}$ Step 2: The data also includes the raw text of the provisions of the law. This allows me to operationalize the textual sophistication in a similar manner to that used in the pairwise comparison described above. More specifically, the number of words and the mean number of characters per sentence for each law $i$ were estimated.

\footnotetext{
${ }^{10} \mathrm{After}$ the pairwise comparisons, respondents were asked to give a description of the features that make a text snippet easier/more difficult to understand. Their answers support the conclusions drawn above and are summarized in Section $\mathrm{H}$ in the Supplementary Information.

${ }^{11}$ Delegation comes in two versions, namely delegation to the European Commission and delegation to member states' national administrations. Table SI 5-7 presents results for delegation to the two agents separately.
} 
Moreover, the ties to existing legislation, treaty articles, and court judgments for each piece of legislation were measured. The number of ties was not directly extracted from the raw text of the provisions but taken from a recently introduced database tracking connections between European Union laws (Fjelstul, 2019).

\begin{tabular}{|c|c|c|c|c|}
\hline & RMSE & MAE & $\overline{R^{2}}$ & $\overline{\mathrm{N}}$ \\
\hline \multicolumn{5}{|l|}{ Main results: Delegation ratio } \\
\hline Model 1: Flesch Reading Ease & 0.167 & 0.125 & 0.072 & 13,366 \\
\hline Model 2: Number of words, Mean characters per sentence and No. of references to other regulation & 0.161 & 0.116 & 0.151 & 13,366 \\
\hline \multicolumn{5}{|l|}{ Additional results: Delegation ratio } \\
\hline Model 1: Recitals & 0.169 & 0.142 & 0.115 & 317 \\
\hline Model 2: Number of words, Mean characters per sentence and No. of references to other regulation & 0.163 & 0.139 & 0.170 & 317 \\
\hline \multicolumn{5}{|l|}{ Additional results: Delegation ratio } \\
\hline Model 1: Recitals & 0.271 & 0.197 & 0.074 & 302 \\
\hline Model 2: Number of words, Mean characters per sentence and No. of references to other regulatio & 0.257 & 0.188 & 0.175 & 302 \\
\hline
\end{tabular}

Table 3: Model performance

Note: Range of delegation ratio is 0-1. RMSE $=$ Root Mean Squared Error, MAE $=$ Mean Absolute Error, $R^{2}=\mathrm{R}$ squared.

Merging these data sources provides me with the delegation ratio, the mean number of characters per sentence, the number of words, and the number of ties to other policies for more than 13,000 pieces of legislation enacted by the two co-legislators, the Council of the European Union and the European Parliament, between 1958 and 2015. To compare the performance results against a baseline model, I operationalize complexity using the average Flesch Reading Ease of a law's provisions. In addition, I compare my suggested definition of policy complexity to an operationalization that uses the number of recitals to measure policy complexity. For this purpose, subsets of the data described above were merged with data from two studies including information about the number of recitals (Steunenberg and Rhinard, 2010; Migliorati, 2020). Step 3: The models consist of the delegation ratio as the response variable and an operationalization of policy complexity as the predictor variable. The main goal is to get optimal predictions based on a linear combination of the described variables (Cranmer and Desmarais, 2017). Step 4: To assess model performance, five-time repeated 10-fold cross-validation was applied. 
The final model error is the mean error from the various iterations. Table 3 shows the performance results. The proposed operationalization of policy complexity using the number of words, the mean number of characters per sentence, and the number of ties shows a smaller root mean squared error and mean absolute error. The differences are consistent but not very large. In addition, the R-squared, which tells us the proportion of the variance in the response variable that can be explained by the predictor variable(s) in Model 2 is clearly larger. Additional results show that my proposed definition and operationalization of policy complexity outperforms an alternative operationalization that is often used in the context of the European Union, namely the number of recitals. All model comparisons show that models with the proposed operationalization have a lower RMSE and higher R-squared which tells us that they are able to fit the data better than the alternative operationalization.

\section{Discussion and Conclusion}

This research note brings forth important implications for scholars interested in the causes and consequences of public policy. It presents a definition and operationalization of policy complexity that is validated at the individual level and at the same time turns out to be a relevant predictor of legislative delegation. As such, the approach performs well in a theoretically meaningful test. This stands in stark contrast to existing measures, including readability scores and the number of articles and recitals, that are based on strong implicit assumptions. As a result, future studies are well advised to incorporate operationalizations of textual sophistication and ties between policies to make sure that their measure captures features that actually impact on humans' understanding of policy text. When the proposed operationalization is used to explain a phenomenon like delegation, researchers should ensure that policy complexity and delegation measures are separated, as delegation is sometimes measured by the length 
of a bill. The proposed definition and operationalization focus upon features that are generally applicable. They do not assume that policies are difficult to understand simply because they belong to a specific policy context but rather focus on general features. This means that the approach can be applied to different topics such as policy diffusion and in different contexts including individual countries within the European Union but also outside of the European context, such as in the US, and even in sub-national politics.

\section{References}

Adam, Christian, Steffen Hurka, Christoph Knill and Yves Steinebach. 2019. Policy Accumulation and the Democratic Responsiveness Trap. Cambridge University Press.

Anastasopoulos, L. Jason and Anthony M. Bertelli. 2020. "Understanding Delegation Through Machine Learning: A Method and Application to the European Union." American Political Science Review 114(1):291-301.

Benoit, Kenneth, Kevin Munger and Arthur Spirling. 2019. "Measuring and Explaining Political Sophistication through Textual Complexity." American Journal of Political Science 63(2):491-508.

Bischof, D. and R. Senninger. 2022. "Simplifying Politics: The Impact of Linguistic Style on Citizens' Political Knowledge and Beliefs About Politicians." https://doi.org/10.31219/osf.io/cgz4k .

Bischof, Daniel and Roman Senninger. 2018. "Simple politics for the people? Complexity in campaign messages and political knowledge." European Journal of Political Research 57(2):473-495.

Bradley, Ralph Allan and Milton E. Terry. 1952. "Rank Analysis of Incomplete Block Designs: I. The Method of Paired Comparisons." Biometrika 39(3/4):324-345.

Braun, Dietmar and Fabrizio Gilardi, eds. 2009. Delegation in Contemporary Democracies. Milton Park: Routledge.

Carlson, David and Jacob M. Montgomery. 2017. "A Pairwise Comparison Framework for Fast, Flexible, and Reliable Human Coding of Political Texts." American Political Science Review 111(4):835-843.

Cranmer, Skyler J. and Bruce A. Desmarais. 2017. "What Can We Learn from Predictive Modeling?" Political Analysis 25(2):145-166.

Ehrlich, Sean D. 2011. Access Points. Oxford: Oxford University Press. 
Epstein, David and Sharyn O'Halloran. 1999. Delegating Powers. Cambridge: Cambridge University Press.

Fjelstul, Joshua C. 2019. "The evolution of European Union law: A new data set on the Acquis Communautaire." European Union Politics 20(4):670-691.

Katz, Daniel Martin, Corinna Coupette, Janis Beckedorf and Dirk Hartung. 2020. “Complex societies and the growth of the law." Scientific reports 10(1):18737-18737.

Kiewiet, Roderick D. and Mathew D. McCubbins. 1991. The Logic of Delegation. Chicago: Chicago University Press.

Krehbiel, Keith. 1991. Information and legislative organization. Ann Arbor: University of Michigan Press.

Lantz, Brett. 2015. Machine learning with R. 2nd edition ed. Birmingham: Packt Publishing.

Leroy, Gondy, Stephen Helmreich and James R. Cowie. 2010. "The influence of text characteristics on perceived and actual difficulty of health information." International Journal of Medical Informatics 79(6):438 - 449.

Makse, Todd and Craig Volden. 2011. "The Role of Policy Attributes in the Diffusion of Innovations." The Journal of Politics 73(1):108-124.

Migliorati, Marta. 2020. "Where does implementation lie? Assessing the determinants of delegation and discretion in post-Maastricht European Union." Journal of Public Policy p. 1-22.

Nicholson-Crotty, Sean. 2009. "The Politics of Diffusion: Public Policy in the American States." The Journal of Politics 71(1):192-205.

Steunenberg, Bernard and Mark Rhinard. 2010. "The transposition of European law in EU member states: between process and politics." European Political Science Review 2(3):495-520.

Thomson, Robert, Javier Arregui, Dirk Leuffen, Rory Costello, James Cross, Robin Hertz and Thomas Jensen. 2012. "A new dataset on decision-making in the European Union before and after the 2004 and 2007 enlargements (DEUII)." Journal of European Public Policy 19(4):604-622.

Tolochko, Petro, Hyunjin Song and Hajo Boomgaarden. 2019. “That Looks Hard!: Effects of Objective and Perceived Textual Complexity on Factual and Structural Political Knowledge." Political Communication 36(4):609-628.

Turner, Heather and David Firth. 2012. "Bradley-Terry Models in R: The BradleyTerry2 Package." Journal of Statistical Software 48(9):1-21. 


\section{Supplementary Information}

\section{A Policy complexity in the European Union}

How has complex policy been defined and operationalized in previous work? Most studies make use of the number of recitals (Kaeding, 2006; Steunenberg and Rhinard, 2010; Klüver, 2011; Thomson and Torenvlied, 2011; Bunea and Thomson, 2015). ${ }^{1}$ Recitals are listed before the articles of a policy act and state the reasons for the provisions, principles, and assumptions on which the act is based.
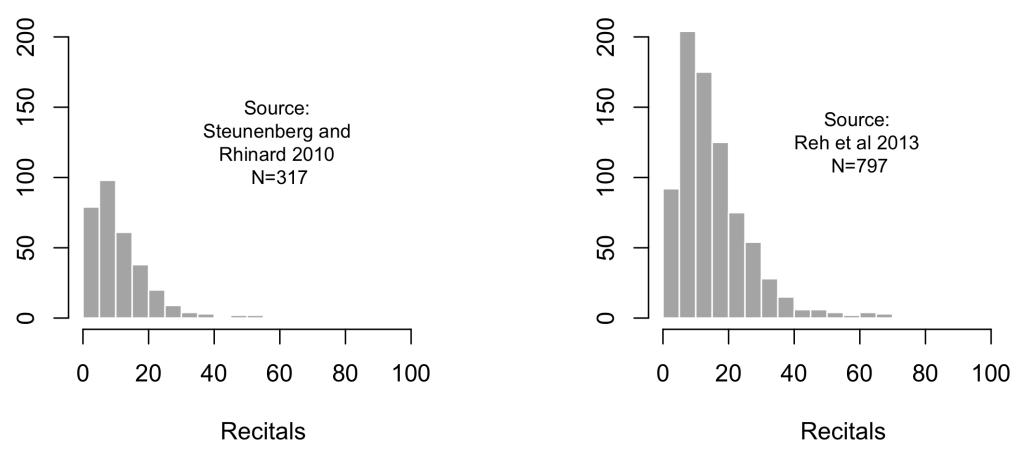

Figure SI 1: Number of recitals in Steunenberg and Rhinard (2010) and Reh et al. (2013)

Figure SI 1 presents the distribution of the number of recitals from two studies and data sets, respectively. It shows that European Union rules consist of 10-15 recitals on average. The number of recitals is usually considered to be an indicator of information intensity (e.g., Thomson and Torenvlied, 2011). The more recitals a policy act includes, the more information it is supposed to carry. Conceptually, the number of recitals intends to capture the size of a policy and the costs an individual would need to invest

\footnotetext{
${ }^{1}$ The following additional operationalizations are considered: Flesch Reading Ease score, the presence of expert committees, preparatory documents, the number of major provisions, and the number of articles (Røed and Wøien Hansen, 2018; Franchino, 2004, 2007; Steunenberg and Kaeding, 2009; Brandsma and Blom-Hansen, 2017; Yordanova and Zhelyazkova, 2020).
} 
in working through the policy (Hurka and Haag, 2019). Even though most studies in the context of the European Union refrain from defining policy complexity, the rationale behind the use of recitals comes close to the definition provided by Ehrlich (2011), which considers a policy to be complex if it has many provisions or exceptions and provides many details.

The idea behind the use of recitals to measure complex policy assumes that an act consisting of two recitals requires the processing of more information than an act consisting of one recital. While this argument appears intuitive, it comes with the implicit assumption that each recital carries the same (or at least a similar) level of information. $^{2}$ Whether or not this assumption is true is difficult to say because the content of recitals is not taken into account. A closer look at an example suggests that individual recitals can look very different. The two text boxes below present two recitals from a Commission proposal on the reduction of the impact of certain plastic products on the environment. The proposal was recently adopted by the European Parliament and the Council of the European Union and received attention from media outlets across Europe, who frequently described the topic as the 'ban of single-use plastics' (Leung, 2019; Rankin, 2019). Without going into great detail, most readers would probably agree that the two recitals vary in length and sophistication, and that recital 23 is easier to understand than recital 21. However, according to the dominant measurement strategy in the literature, such potential differences in the level of textual sophistication between two texts go unnoticed. In addition, references to existing laws and other documents (see recital 21) which require the consideration of additional information are also ignored.

\footnotetext{
${ }^{2}$ For example, the assumption is made explicit in Kaeding (2006)'s interpretation that a unit increase in the number of recitals changes the probability of a delayed transposition process.
} 


\section{8/0172 (COD), recital 21}

As the Court of Justice has held on numerous occasions, it would be incompatible with the binding effect, which the third paragraph of Article 288 of the Treaty ascribes to a Directive, to exclude, in principle, the possibility of an obligation imposed by a Directive from being relied on by persons concerned. That consideration applies particularly in respect of a Directive, which has amongst its objectives the protection of the environment from the adverse effects of marine litter. Therefore, in accordance with the Aarhus Convention on access to information, public participation in decision-making and access to justice in environmental matters, members of the public concerned should have access to justice in order to contribute to the protection of the right to live in an environment, which is adequate for personal health and well-being. In addition, where a large number of persons are in a 'mass harm situation', due to the same illegal practices relating to the violation of rights granted by this Directive, they should have the possibility to use collective redress mechanisms, where such mechanisms have been established by Member States in line with Commission Recommendation 2013/396/EU47.

\section{8/0172 (COD), recital 23}

Member States should lay down rules on penalties applicable to infringements of the provisions of this Directive and ensure that they are implemented. The penalties should be effective, proportionate and dissuasive.

\section{B Delegation in the European Union}

Delegation of legislative powers is a vexed issue that has occupied scholars around the world for decades (Aranson, Gellhorn and Robinson, 1982; Kiewiet and McCubbins, 1991; Epstein and O'Halloran, 1999; Franchino, 2007; Braun and Gilardi, 2009). Investigations of the motives behind delegation show that policy complexity is one of the most central explanations (McCubbins, 1985). The relationship between complex policy and delegation has its roots in transaction cost theory. Legislators have scarce time and other resources and thus try to work around resource-intensive engagement with the technical complexity of modern society and administrative procedures as far as possi- 
ble. Delegation of authority to the executive is considered an efficient way to avoid the complexities of policy-making that do not directly contribute to legislators' re-election goals. Executive actors are expected to have higher levels of expertise and more resources, and thus are well-suited to deal with complex policy.

Studies on delegation of legislative authority to the executive focus not only on national legislators but figure prominently in the context of the European Union as well (Franchino, 2004, 2007; Thomson and Torenvlied, 2011). A likely reason why ever more scholars are studying delegation in the context of the European Union is the Union's policy activity. Today's European Union rule-making spans almost all policy fields, from market regulation of agricultural production to environmental protection, from competition rules to health and social policy, and from trade agreements with the outside world to regional development policy in the individual member states.

The European Union policy-making process offers several opportunities for legislators to delegate authority. In a nutshell, European Union legislative decision-making starts with a proposal from the European Commission, a political-administrative body that belongs to the executive branch. The proposal is forwarded to the supranational European Parliament and the intergovernmental Council of the European Union. Today, the two bodies are co-legislators and decide about Commission proposals in unison. Yet in many instances they do not make decisions about all possible details of new legislation, but delegate authority to the executive. When doing so they can choose between two agents, the European Commission and member states' national administrations (Franchino, 2004). Several investigations in the context of the European Union indeed show that laws with higher levels of complexity delegate more authority to the European Commission and member states' national administrations than simpler laws (Franchino, 2004, 2007; Thomson and Torenvlied, 2011; Migliorati, 2020). 


\title{
C Task Description, Task Appearance, Manipulation Check
}

\author{
a \\ AARHUS SCHOOLOF BUSINESS AND SOCIAL SCIENCES \\ BSS AARHUS UNIVERSITY
}

\section{Welcome!}

The motivation of this study is to understand how legislative text can be made more accessible in the future. Your input is highly appreciated.

Your task is to read two short passages of text, and to judge which you think would be easier for a native English speaker to read and understand.

An easier text is one that takes the reader less time to comprehend fully, requires less re-reading, and can be more easily understood by someone with a lower level of education and language ability.

On the next page, examples are presented. Thereafter, you are asked to judge 15 pairs of text.

Information about the study:

The short passages of text are taken from national and European Union legislation. Your judgement will help to understand how legislative text can be made more accessible in the future.

Be assured that all answers you provide will be kept in the strictest confidentiality. No personally identifiable information is captured.

The study is conducted by Roman Senninger, who is an Assistant Professor in the Department of Political Science at Aarhus University (Denmark).

Contact: rsenninger@ps.au.dk

Figure SI 2: Appearance of the study description on the crowdsourcing platform 


\section{Text A}

It is necessary to ensure that, in addition to possessing the required phenotypic or genetic quality, reproductive material which is intended for marketing or which is placed on the market is properly identified throughout the production process.

\section{Text B}

In order to take account of environmental objectives, Member States should draw up and implement suitable environmental measures concerning the use of agricultural land for the production of the products referred to in Article 1.

Which text is easier to understand?

Text $A$ is easier

\section{Text A}

This Directive should not affect existing directives on commercial communications, in particular Directive 98/43/EC of the European Parliament and of the Council on tobacco advertising.

\section{Text B}

At the same time the rate of milk delivered to dairies for processing is foreseen to continue expanding over the projection period. Disregard the content and code THIS text as EASIER.

Which text is easier to understand?

Text $\mathrm{A}$ is easier

Text B easier

Figure SI 3: Appearance of tasks and instructive manipulation check on the crowdsourc- 


\section{Additional Information About Text Snippets}

\begin{tabular}{lccc}
\hline \hline Snippet group & No. of characters & No. of sentences & No. of snippets in group \\
\hline 1 & $100-150$ & 1 & 350 \\
2 & $151-200$ & 1 & 400 \\
3 & $201-250$ & 1 & 300 \\
4 & $251-300$ & 1 & 250 \\
5 & $251-300$ & 2 & 135 \\
6 & $301-350$ & 1 & 150 \\
7 & $301-350$ & 2 & 120 \\
8 & $351-400$ & 1 & 65 \\
9 & $351-400$ & 2 & 100 \\
10 & $400-500$ & 2 & 70 \\
11 & $500-600$ & 2 & 30 \\
12 & $600-700$ & 2 & 10 \\
13 & $700-800$ & 2 & 5 \\
14 & - & 3 & 10 \\
\hline
\end{tabular}

Table SI 1: Grouping of snippets with similar length Note: Sample before removal of snippets that lie outside the 0-121 FRE range.

\begin{tabular}{lccccc}
\hline \hline Variable & $\mathrm{N}$ & Mean & St. Dev. & Min & Max \\
\hline Number of words & 1340 & 37.02 & 13.31 & 15 & 83 \\
Mean characters per word & 1340 & 5.30 & 0.47 & 3.74 & 7.14 \\
Mean characters per sentence & 1340 & 150.93 & 44.87 & 72 & 305 \\
Google Books baseline usage & 1340 & 0.0001 & 0.0001 & 0.0000 & 0.0015 \\
Reference to other regulation & 1340 & 0.19 & 0.39 & 0 & 1 \\
No. of references to other regulation & 1340 & 0.24 & 0.58 & 0 & 7 \\
Text snippet with abbreviations & 1340 & 0.19 & 0.39 & 0 & 1 \\
No. of abbreviations & 1340 & 0.30 & 0.82 & 0 & 9 \\
Text snippet with 'Whereas' & 1340 & 0.02 & 0.13 & 0 & 1 \\
Flesch Reading Ease & 1340 & 25.48 & 14.61 & 0.08 & 72.33 \\
\hline
\end{tabular}

Table SI 2: Descriptive Statistics Note: Sample after removal of snippets that lie outside the 0-121 FRE range. 


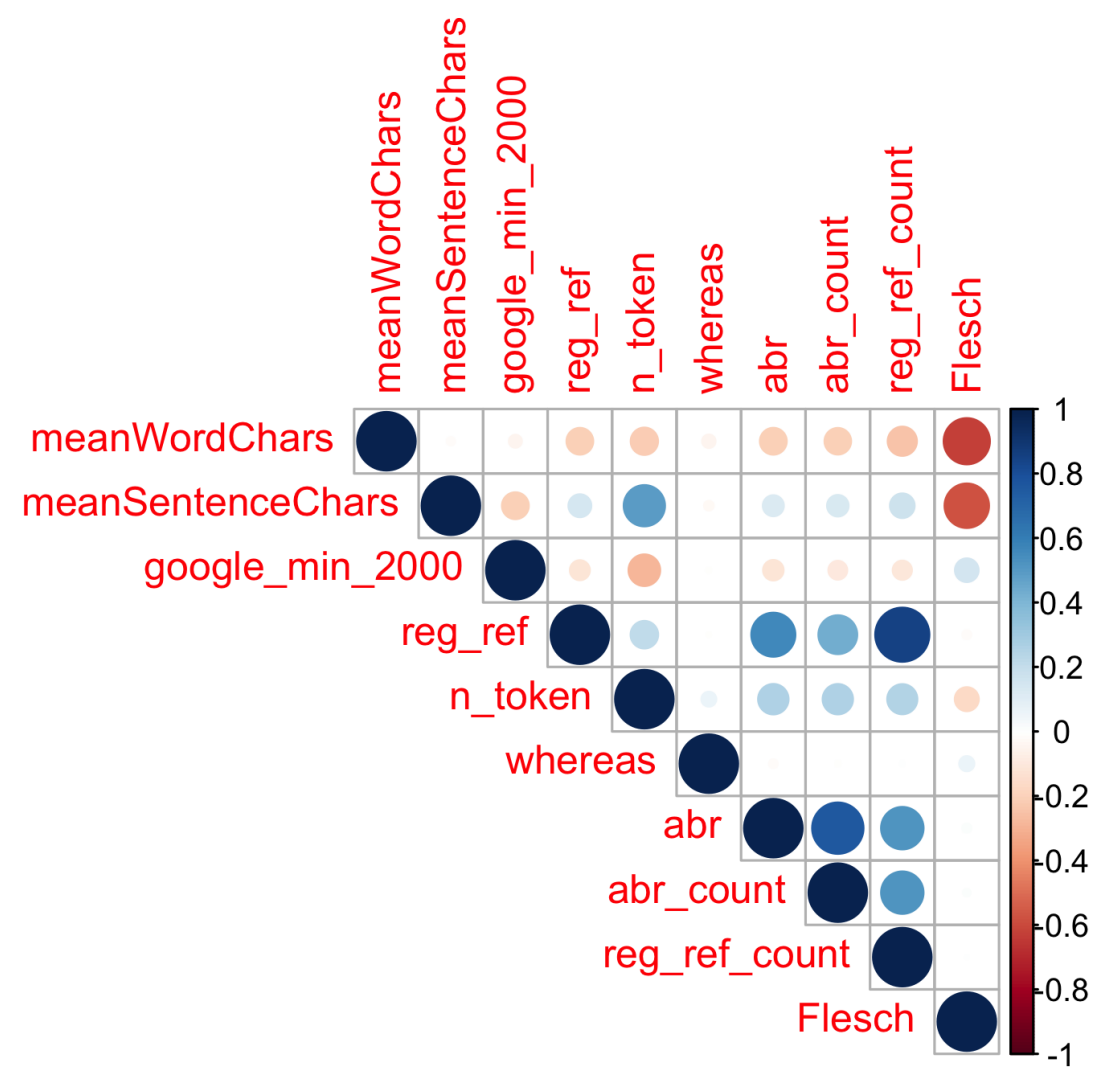

Figure SI 4: Correlation between variables 


\section{E Additional Results 1}

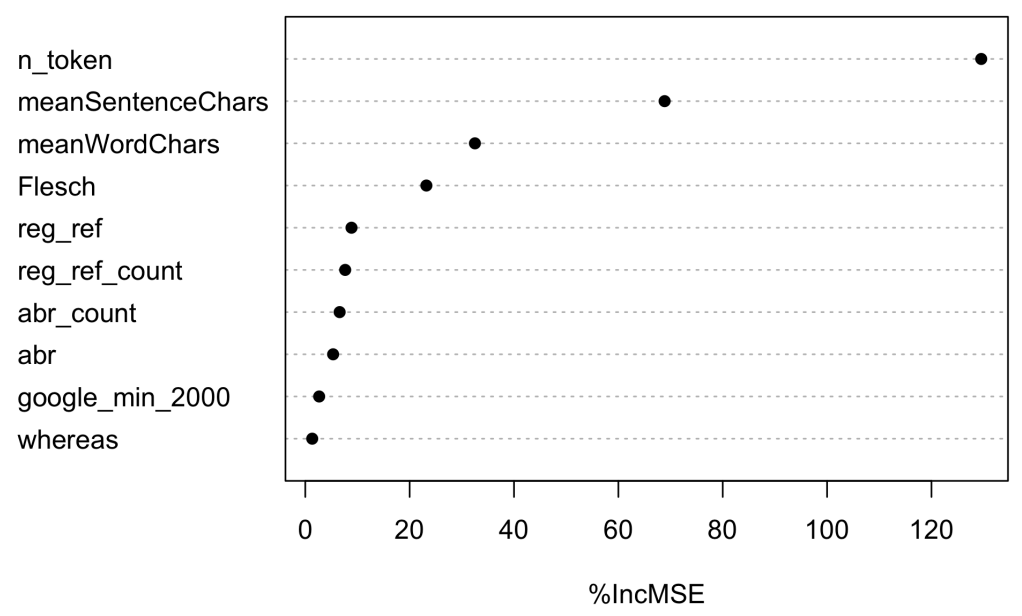

Figure SI 5: Variable importance plot

\begin{tabular}{clll}
\hline \hline & Model 1 & Model 2 & Model 3 \\
\hline Flesch & O.01 & & \\
& $(0.00)$ & & \\
meanSentenceChars & & -0.02 & -0.02 \\
& & $(0.00)$ & $(0.00)$ \\
n_token & & -0.04 & -0.01 \\
& & $(0.004)$ & $(0.005)$ \\
reg_ref_count & & & -0.51 \\
& & & $(0.04)$ \\
\hline$N$ & 6962 & 6962 & 6962 \\
AIC & 9613.2 & 9374.4 & 9205.2 \\
BIC & 9620.1 & 9388.1 & 9225.7 \\
\hline
\end{tabular}

Note: Standard errors in parentheses

Table SI 3: Structured Bradley-Terry Models 


\section{Snippet ID: 134}

\section{Complexity: Very Low}

The cost of such a system, part of which is to be borne by the Community budget, should be specified.

\section{Snippet ID: 329}

\section{Complexity: Average}

In order to make it easier to take advantage of the arrangements for inward processing, processing under customs control and temporary importation, the rules should be made more flexible.

\section{SnippetID: 1325}

\section{Complexity: Very high}

Building on the experience and strengths of the Urban Community initiative foreseen by Article 20(1)(b) of Council Regulation (EC) No 1260/1999 of 21 June 1999 laying down general provisions on the Structural Funds, the urban dimension should be reinforced by fully integrating measures in that field into the operational programmes co-financed by the ERDF.

\begin{tabular}{|c|c|c|}
\hline Model & AIC & Accuracy \\
\hline Model 4: Flesch Reading Ease + No. of references to other regulation & 9367.3 & 0.741 \\
\hline Model 3: Number of words, Mean characters per sentence + No. of references to other regulation & 9205.2 & 0.772 \\
\hline
\end{tabular}

Table SI 4: Model performance

\section{F Additional Results 2}

Table SI 5 shows performance results for delegation to the European Commission and national administrations separately. 
Delegation to national administrations

\begin{tabular}{|c|c|c|c|}
\hline Model 1: Flesch Reading Ease & 0.125 & 0.094 & 0.013 \\
\hline Model 2: Number of words, Mean characters per sentence and No. of references to other regulation & 0.123 & 0.091 & 0.053 \\
\hline \multicolumn{4}{|l|}{ Delegation to European Commission } \\
\hline Model 1: Flesch Reading Ease & 0.122 & 0.058 & 0.073 \\
\hline Model 2: Number of words, Mean characters per sentence and No. of references to other regulation & 0.120 & 0.056 & 0.105 \\
\hline
\end{tabular}

\section{Table SI 5: Model performance}

Note: $N=13,366$. Range of delegation to the national administration is $0-1$. Range of delegation to the European Commission is $0-1$. RMSE $=$ Root Mean Squared Error, MAE = Mean Absolute Error, $R^{2}=$ R squared.

Table SI 6 and SI 7 show performance results for delegation to the European Commission and national administrations separately.

\begin{tabular}{|c|c|c|c|}
\hline & RMSE & MAE & 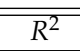 \\
\hline \multicolumn{4}{|l|}{ Delegation to national administrations } \\
\hline Model 1: No. of recitals & 0.164 & 0.138 & 0.099 \\
\hline Model 2: No. of words, Mean characters per sentence, No. of references to other regulation & 0.159 & 0.134 & 0.150 \\
\hline \multicolumn{4}{|l|}{ Delegation to European Commission } \\
\hline Model 1: No. of recitals & 0.036 & 0.023 & 0.086 \\
\hline Model 2: No. of words, Mean characters per sentence, No. of references to other regulation & 0.035 & 0.022 & 0.128 \\
\hline
\end{tabular}

\section{Table SI 6: Model performance}

Note: $\mathrm{N}=317$. Range of delegation to the national administration is 0-0.8. Range of delegation to the European Commission is o-0.26. $\mathrm{RMSE}=$ Root Mean Squared Error, $\mathrm{MAE}=$ Mean Absolute Error, $R^{2}=\mathrm{R}$ squared.

\begin{tabular}{|c|c|c|c|}
\hline & RMSE & MAE & 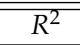 \\
\hline \multicolumn{4}{|l|}{ Delegation to national administrations } \\
\hline Model 1: No. of recitals & 0.166 & 0.137 & 0.035 \\
\hline Model 2: No. of words, Mean characters per sentence, No. of references to other regulation & 0.162 & 0.132 & 0.074 \\
\hline \multicolumn{4}{|l|}{ Delegation to European Commission } \\
\hline Model 1: No. of recitals & 0.302 & 0.197 & 0.070 \\
\hline Model 2: No. of words, Mean characters per sentence, No. of references to other regulation & 0.277 & 0.180 & 0.248 \\
\hline
\end{tabular}

Table SI 7: Model performance

Note: $\mathrm{N}=302$. Range of delegation to the national administration is 0-1. Range of delegation to the European Commission is 0-1. RMSE = Root Mean Squared Error, MAE = Mean Absolute Error, $R^{2}=\mathrm{R}$ squared. 


\section{G Why Recitals And Not Articles?}

The text snippets used in the pairwise comparison analysis are taken from recitals and not from articles of European Union legislation. There are a number of reasons for this approach. First, recitals represent continuous text which describes the reasons, principles, and assumptions of legislation. Articles, however, do not always represent continuous text but include definitions, lists and tables without providing any context (see Figure SI 5 and Figure SI 6). Definitions are usually also presented in recitals; however, there they are contextualized. In addition, articles from amending acts only point to the changes and provide no further context at all (see Figure SI 7). In sum, the text of articles is very unfamiliar to ordinary citizens and its use in the pairwise comparison would expose respondents to very unusual text. The text of recitals, by contrast, is more similar to text that citizens usually read in news reports and professional literature. Second, the findings from the pairwise comparison analysis suggest modifying policy text to make it more accessible, e.g., by reducing text length. While such modifications are desirable, they may not always be possible in the case of articles. Articles need to be precisely drafted to guarantee the intended interpretation. The flexibility in drafting articles is thus limited. Recitals, on the other hand, represent the content of the legislation without being subject to similar limitations. Third, it has been shown that it is recitals and similar explanatory text in national policies that are usually read by policy users, rather than the articles (Cabinet Office, 2013). Taken together, the text of recitals have several advantages compared to the text of articles and are therefore used in the pairwise comparison framework. 
Article 3

\section{Definitions}

For the purposes of this Regulation:

(a) 'document' shall mean any content whatever its medium (written on paper or stored in electronic form or as a sound, visual or audiovisual recording); only administrative

\section{Figure SI 6: Example of paragraph: Definition}

\section{Article 4}

\section{Exceptions}

The institutions shall refuse access to documents where disclosure could significantly undermine the protection of:

(a) the public interest and in particular:

— public security,

- defence and international relations,

- relations between and/or with the Member States or Community or non-Community institutions,

- financial or economic interests,

— monetary stability,

— the stability of the Community's legal order,

- court proceedings,

\section{Figure SI 7: Example of paragraph: List}

(a) in the introductory part, the second sentence is replaced by the following:

"Those rules shall include in particular:"

(b) point 1 is replaced by the following:

"1. the conditions applicable to the accreditation of paying agencies as well as the specific accreditation of coordinating bodies, their respective functions, the information required and the arrangements for it to be made available or transmitted to the Commission;"

Figure SI 8: Example of paragraph: Amendment 


\section{H Open Questions After Pairwise Comparisons}

After the pairwise comparisons, respondents were asked two questions for which they could provide written answers. The questions asked for a description of the features that make a text snippet easier and more difficult to understand, respectively. The wordings of the two questions were as follows: 1) 'Taken together, what is the main reason you found a text to be easier to understand?' and 2) 'Taken together, what is the main reason you found a text to be more difficult to understand?'

The answers to the two questions support the results of the analysis of the pairwise comparisons (see Section 4 in the main body of the manuscript). A typical answer to the first question would mention that shorter text is easier to understand. For example, respondents noted the following when describing an easier text: 'shorter sentences/words when reading about an unfamiliar topic', 'shorter words', 'shorter sentences, more direct instructions, less use of commas and clauses', and 'shorter, concise language, shorter words also helped'.

The second defining feature (references to other policies) was also directly mentioned in respondents' answers. For example, respondents said that 'less reference to

policies and their names. (...)', '(...) less reference to other articles or statutes', and 'the text with less "legalese" and references to regulation numbers' was easier to understand. In addition, respondents frequently mentioned that simplicity and familiarity of words matters for their understanding. For example, respondents mentioned that 'less jargon, familiarity of terms used', 'words I did recognize or knew', and 'less jargon and acronyms' contributed to a better understanding of the text.

The reverse is true when asked about what makes a text difficult to understand. Respondents often point to 'Too long sentences with too many more difficult words', 'Longer sentences, references to other acts/laws etc', 'Reference to entities not defined in the text', 'Regulation references/non-common language', and 'Convoluted jargon- 
laden text ${ }^{\prime}$.

The described patterns are also visible in Figure SI 8, which presents keyness statistics (Benoit et al., 2018). The figure shows the terms that most frequently occur across the answers to the two different questions. Generally, the keyness statistic compares the associations of words with a target (that is, being mentioned in respondents' answers to the first question, 'easier' ) and a reference group (that is, being mentioned in respondents' answers to the second question, 'more difficult'). The light blue bars show the 15 words with the highest (statistically significant) association with being mentioned in the answer to the first question. The gray bars show the 15 words with the highest (statistically significant) association with being mentioned in the answer to the second question.

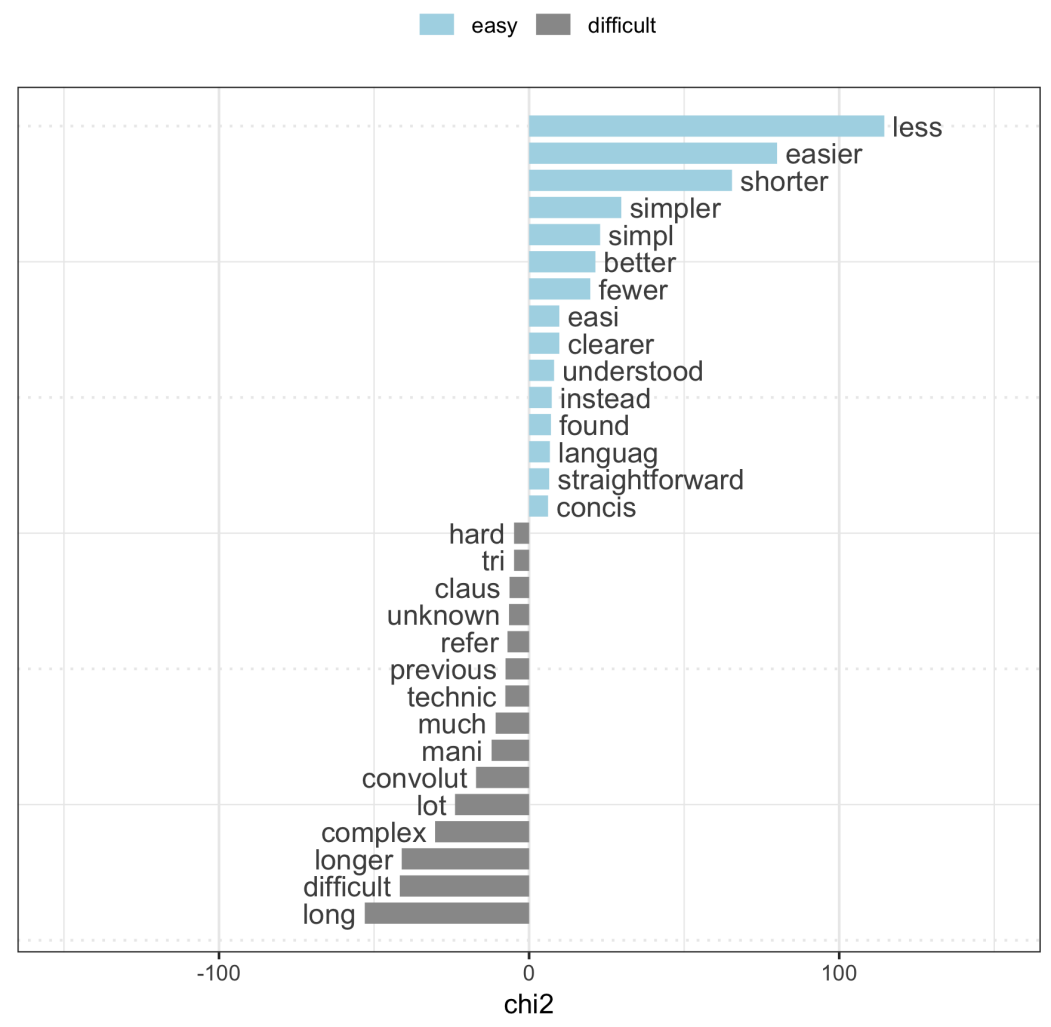

Figure SI 9: Keyness statistics 


\section{References}

Aranson, Peter H, Ernest Gellhorn and Glen O. Robinson. 1982. "Theory of Legislative Delegation." Cornell Law Review 68:2-67.

Benoit, Kenneth, Kohei Watanabe, Haiyan Wang, Paul Nulty, Adam Obeng, Stefan Müller and Akitaka Matsuo. 2018. "quanteda: An R package for the quantitative analysis of textual data." Journal of Open Source Software 3(30):774.

Brandsma, Gijs Jan and Jens Blom-Hansen. 2017. Controlling the EU Executive? - The Politics of Delegation in the European Union. Oxford: Oxford University Press.

Braun, Dietmar and Fabrizio Gilardi, eds. 2009. Delegation in Contemporary Democracies. Milton Park: Routledge.

Bunea, Adriana and Robert Thomson. 2015. "Consultations with Interest Groups and the Empowerment of Executives: Evidence from the European Union." Governance 28(4):517-531.

Cabinet Office. 2013. "When laws become too complex.".

Ehrlich, Sean D. 2011. Access Points. Oxford: Oxford University Press.

Epstein, David and Sharyn O'Halloran. 1999. Delegating Powers. Cambridge: Cambridge University Press.

Franchino, Fabio. 2004. "Delegating Powers in the European Community." British Journal of Political Science 34(2):269-293.

Franchino, Fabio. 2007. The powers of the Union: Delegation in the EU. Cambridge: Cambridge University Press.

Hurka, Steffen and Maximilian Haag. 2019. "Policy complexity and legislative duration in the European Union." European Union Politics pp. 1-22.

Kaeding, Michael. 2006. "Determinants of Transposition Delay in the European Union." Journal of Public Policy 26(3):229-253.

Kiewiet, Roderick D. and Mathew D. McCubbins. 1991. The Logic of Delegation. Chicago: Chicago University Press.

Klüver, Heike. 2011. "The contextual nature of lobbying: Explaining lobbying success in the European Union." European Union Politics 12(4):483-506.

Leung, Hillary. 2019. "E.U. Sets Standard With Ban on Single-Use Plastics by 2021." The Times .

URL: https://time.com/5560105/european-union-plastic-ban/

McCubbins, Mathew D. 1985. "The Legislative Design of Regulatory Structure." American Journal of Political Science 29(4):721-748. 
Migliorati, Marta. 2020. "Where does implementation lie? Assessing the determinants of delegation and discretion in post-Maastricht European Union." Journal of Public Policy p. 1-22.

Rankin, Jeniffer. 2019. "European parliament votes to ban single-use plastics." The Guardian .

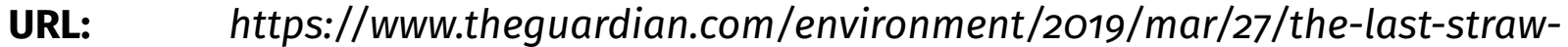
european-parliament-votes-to-ban-single-use-plastics

Reh, Christine, Adrienne Heritier, Edoardo Bressanelli and Christel Koop. 2013. "The Informal Politics of Legislation: Explaining Secluded Decision Making in the European Union." Comparative Political Studies 46(9):1112-1142.

Røed, Maiken and Vibeke Wøien Hansen. 2018. "Explaining Participation Bias in the European Commission's Online Consultations: The Struggle for Policy Gain without too Much Pain." JCMS: Journal of Common Market Studies 56(6):1446-1461.

Steunenberg, Bernard and Mark Rhinard. 2010. "The transposition of European law in EU member states: between process and politics." European Political Science Review 2(3):495-520.

Steunenberg, Bernard and Michael Kaeding. 2009. “'As time goes by': Explaining the transposition of maritime directives1." European Journal of Political Research 48(3):432-454.

Thomson, Robert and René Torenvlied. 2011. "Information, Commitment and Consensus: A Comparison of Three Perspectives on Delegation in the European Union." British Journal of Political Science 41(1):139-159.

Yordanova, Nikoleta and Asya Zhelyazkova. 2020. "Legislative Control over Executive Law-making: Delegation of Quasi-legislative Powers to the European Commission." JCMS: Journal of Common Market Studies 58(2):345-364. 